\title{
Omeg@Silica: In-Silica Stabilization of Sustainable Fish Oil
}

\author{
Claudia Lino, ${ }^{[a]}$ Mario Pagliaro, ${ }^{\left[{ }^{[a]}\right.}$ Rosaria Ciriminna*[a] \\ Abstract: Fish oil rich in docosahexaenoic acid (DHA) and \\ eicosapentaenoic acid (EPA), vitamin $D_{3}$ and natural astaxanthin \\ sustainably extracted from anchovy fillet leftovers using biobased \\ limonene only, can be conveniently stabilized by adsorption on \\ periodic mesoporous silicas. The simplicity of the process, the high \\ load of entrapped fish oil, and the biocompatible nature of silica \\ support numerous forthcoming applications of this new class of \\ "Omeg@Silica” materials.
}

Keywords: Omeg@Silica; periodic mesoporous silica; omega-3; anchovy; fish oil

\section{Introduction}

Inuit populations living in Greenland in the early 1970 s eating only whale, seal and fish meat presenting virtually no cardiovascular disease (and no diabetes mellitus) were found to have high levels of two omega-3 long chain polyunsaturated fatty acids, DHA and EPA, in their plasma and platelet lipids [1]. Following this discovery and a large number of subsequent biochemical and clinical studies [2], fish oil rich in EPA and DHA omega-3 lipids has become the active ingredient in a variety of nutraceuticals and dietary supplements with multiple health benefits, starting from reducing cardiovascular risk and tissue inflammation [3].

To increase intake of omega-3 lipids, whose recommended daily intake is not met by the population of most economically developed countries, marine oil rich in EPA and DHA are added also to "fortified" milk powders (including infant formulas) [4] and to animal feed for example to produce omega-3 enriched eggs [5].

One of the main deficiencies in diets common to industrially developed countries is the insufficient consumption of EPA and DHA, which has led to the introduction of a new index (EPA+DHA in red blood cells) directly responsive to changes in $E P A+D H A$ intake [6]. Increasing the amount of EPA+DHA essential fatty acids in the body requires to either increase consumption of fish and seafood in the diet or omega-3 supplementation.

Increasing global awareness of this diet deficiency has led to a global and increasing demand of fish oil which, in its turn, is threatening marine wildlife by enhancing overfishing [7]. Accordingly, shifting the production of fish oil, the main ingredient of omega-3 dietary supplements, from fish to fish processing waste produced in huge yearly amounts by the fish

[a] Dr. C. Lino, Dr. M. Pagliaro, Dr. R. Ciriminna Istituto per lo Studio dei Materiali Nanostrutturati, CNR via U. La Malfa 153 90146 Palermo (Italy)

E-mail: rosaria.ciriminna@cnr.it

\author{
processing industry is an urgent global need [8].
}

In this context, we recently reported a new circular approach to the production of high quality fish oil involving the solid-liquid extraction of anchovy fillet leftovers using citrus-derived $d$ limonene as green biosolvent [9]. The terpene, which is also an antioxidant [10], protects PUFAs in the fish oil from otherwise quick catalytic oxidation due to free radicals formed in the presence of air's oxygen [11], both during the fish oil extraction at room temperature and during solvent recovery by evaporation under reduced pressure $(3 \mathrm{mbar})$ at $90^{\circ} \mathrm{C}$ [9].

In general, fish oil in food supplement capsules first undergoes chemical refining and transformation into ethyl esters and then is added with natural or synthetic antioxidants prior to encapsulation in soft gelatin capsules [8]. In other applications, a number of microencapsulation techniques are used by industry to microencapsulate and protect fish oil from peroxidation [12].

To the best of our knowledge, the only fish oil microencapsulation process involving silica was reported by Australia's scholars in 2018 [13]. Spray drying a fish oil submicroemulsion stabilised by food-grade hydrophilic silica particles (Aerosil 300), the team showed that microencapsulation in silica indeed protects the omega-3 lipids from oxidation regardless of the harsh fabrication conditions (inlet temperature, $140{ }^{\circ} \mathrm{C}$ and high pressure) employed to spray dry the functionalized silica particles.

Now, we report the outcomes of encapsulating the newly extracted fish oil obtained from anchovy filleting industrial waste in periodic mesoporous silica particles. Both biocompatible MCM-41 silica and organically modified mesoporous silica materials were used as adsorbent for this new fish oil rich not only in EPA and DHA [9] but also in vitamin $D_{3}$ [14] and natural astaxanthin.

The outcomes of the material synthesis and structural investigation reported in this study suggest that this this new class of materials called "Omeg@Silica" has the potential to expand the biological applications of omega-3 lipids, from better fortified foods, through controlled release in the gastrointenstinal tract.

\section{Results and Discussion}

\section{Experimental}

\section{Fish oil extraction}

Fish oil was extracted from anchovy filleting industrial waste kindly donated by an industry based in Sicily (Agostino Recca Conserve Alimentari) using $d$-limonene as green biosolvent according to the solid-liquid extraction and solvent recovery processes previously described [9]. 


\section{Material Synthesis}

MCM-41 was synthesized by the template-assisted sol-gel process using a published synthetic protocol [15]. In detail, $1 \mathrm{~g}$ of hexadecyltrimethylammonium bromide (CTAB $\geq 99 \%$ pure, Aldrich) and $280 \mathrm{mg}$ of sodium hydroxide (Analyticals, Carlo Erba) were dissolved in $480 \mathrm{~mL}$ of deionized water. An aliquot $(5.4 \mathrm{~mL}$ ) of tetraethylorthosilicate (TEOS $\geq 99 \%$ pure, Aldrich) was added dropwise to the solution. The resulting mixture was kept under continuous mechanical stirring $(400 \mathrm{rpm})$ at $80{ }^{\circ} \mathrm{C}$ for $2 \mathrm{~h}$.

The solid precipitate was recovered by filtration, washed with abundant deionized water and methanol (99.8\% pure, Aldrich) and dried at $60^{\circ} \mathrm{C}$ for $48 \mathrm{~h}$. The residual surfactant entrapped in the silicate was removed via calcination at $550^{\circ} \mathrm{C}$ for $6 \mathrm{~h}$.

Functionalization of MCM-41 silica with 3-amino-propyl groups was achieved by a published post-grafting method [16]. In detail, an aliquot $(600 \mathrm{mg})$ of the as-synthesized MCM- 41 was refluxed in $15 \mathrm{~mL}$ toluene ( $\geq 99.5 \%$ pure, Fluka Chemika) added with 152 $\mu \mathrm{L}$ of 3-amino-propyltrimethoxysilane (APTMS, 0,42 mmol, $97 \%$ pure, Alfa Aesar).

The solution was kept under stirring for $6 \mathrm{~h}$ after which it was decanted. The solid product thereby obtained was washed three times with $15 \mathrm{~mL}$ of isopropanol (99\% pure, J.K. Baker, Fisher Scientific), and dried at $40^{\circ} \mathrm{C}$ for $3 \mathrm{~h}$.

\section{Loading of the Materials with Fish Oil}

The fatty acid composition of anchovy discard fish oil was assessed following the standard method involving transesterification of the oil triglycerides and CG-MS analysis of the respective fatty acid methyl esters using a ThermoScientific Trace 1310/ISQ LT single quadrupole GC/MS spectrometer [9]. The marine oil extracted was once again found to be rich in omega-3 eicosapentaenoic acid (EPA) and docosahexenoic acid (DHA, Table 1).

Table 1. EPA and DHA in fish oil extracted from anchovy waste

\begin{tabular}{|l|l|}
\hline $\begin{array}{l}\text { Polyunsaturated Fatty Acid } \\
\text { (in lipid numbers) }\end{array}$ & Abundance \\
\hline EPA $(20: 5, n-3)$ & $5.4 \%$ \\
\hline DHA $(22: 6, n-3)$ & $12.4 \%$ \\
\hline
\end{tabular}

Loading of the MCM- 41 and of the MCM- 41 organically functionalized with 3-amino-propyl groups (FMCM-41) was carried out by direct adsorption of the oil by adding dropwise the oil to the material kept in a glass flask under agitation. For example, addition of a first $60 \mu \mathrm{L}$ aliquot of fish oil to FMCM-41 $(100 \mathrm{mg})$, was followed by additions of $20 \mu \mathrm{L}$ aliquots. After 8 min, addition of oil was terminated and the material left under agitation for $24 \mathrm{~h}$.

In detail, MCM41 was loaded up to $50 \% \mathrm{w} / \mathrm{w}$ fish oil (MCM41 50\%) (Figure 1), while FMCM41 could be loaded up to $40 \%$ w/W (FMCM-41_40\%).

\section{Characterization}

The materials were characterized by FT-IR spectroscopy (Bruker, ALPHA model), scanning electron microscopy (SEM) and thermogravimetric analysis (Mettler Toledo TGA/DSC). Surface area and porosity were determined from cryogenic nitrogen adsorption-desorption analysis using a Micromeritics ASAP 2020 Plus 1.03 porosimeter.
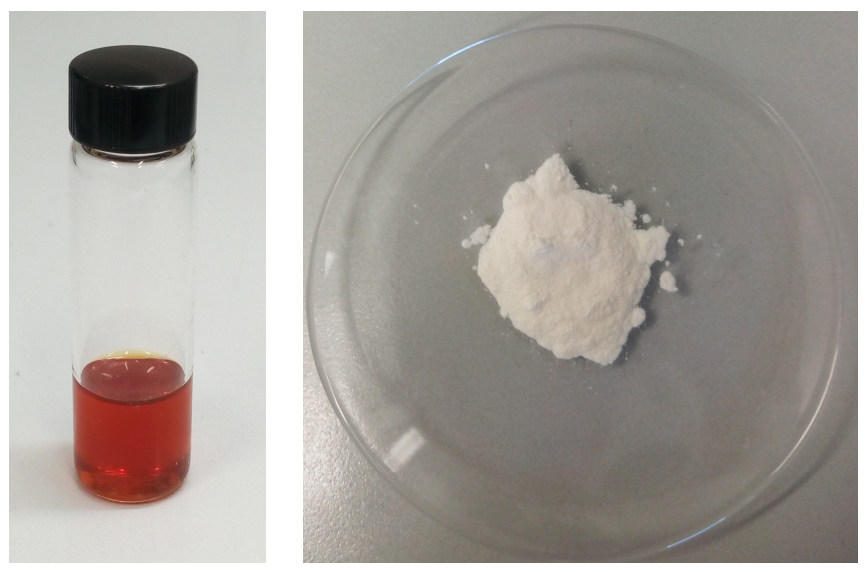

Figure 1. Oil extracted from anchovy filleting waste (left), Omeg@Silica comprised of MCM-41 loaded with $50 \% \mathrm{w} / \mathrm{w}$ fish oil (right).

The SEM analyses were conducted with a SEM Zeiss EVO MA10 microscope. Particle size, polydispersity index (PDI) and zeta-potential were measured with a Zetasizer Nano ZS (Malvern Instrument, United Kingdom) using Dynamic Light Scattering (DLS) after dispersing material samples in distilled water.

\section{Results and Discussion}

The inner porosity of MCM-41 silica is able to encapsulate more oil (50 wt\%) than amino-silica FMCM-41 (40 wt\%). Figure 2 readily shows the reason. Both materials show type IV $\mathrm{N}_{2}$ adsorption-desorption isotherms whose hysteresis loop of moderate steepness is associated with capillary condensation taking place in narrow slit-like mesopores [17].

Table 2. Textural properties of MCM-41 and FMCM-41.

\begin{tabular}{|c|c|c|c|}
\hline Material & $\begin{array}{c}\text { Specific } \\
\text { surface area } \\
\left(\mathrm{m}^{2} / \mathrm{g}\right)\end{array}$ & $\begin{array}{c}\text { Specific pore } \\
\text { volume } \\
\left(\mathrm{cm}^{3} / \mathrm{g}\right)\end{array}$ & $\begin{array}{c}\text { Average pore } \\
\text { diameter }(\mathrm{nm})\end{array}$ \\
\hline MCM-41 & 825 & 0.6 & 2.9 \\
\hline FMCM-41 & 440 & 0.3 & 2.5 \\
\hline
\end{tabular}

However, Table 2 shows the significant decrease of both specific surface area (SSA), specific pore volume (SPV) and average pore diameter of MCM-41 upon grafting the internal pore wall of surface with the amino-propyl group.

Once loaded with $50 \mathrm{wt} \%$ of sustainably sourced anchovy fish oil, the surface area of MCM-41 decreases to $16 \mathrm{~m}^{2} / \mathrm{g}$ (entry 1 in Table 3). Increasing the load of fish oil adsorbed by the aminopropyl-functionalized silica from 10 to $40 \mathrm{wt} \%$, the SSA and the SPV go, respectively, from $166 \mathrm{~m}^{2} / \mathrm{g}$ to $16 \mathrm{~m}^{2} / \mathrm{g}$ and 
from $0.1 \mathrm{~cm}^{3} / \mathrm{g}$ to $0.02 \mathrm{~cm}^{3} / \mathrm{g}$ (entries 2 and 5 in Table 3) providing evidence of the adsorption of the fish oil triglyceride molecules via entrapment in the inner porosity of the silicas.

Table 3. Textural properties of Omeg@Silicas comprised of MCM41 and FMCM-41 loaded with different amount of sustainably extracted fish oil revealed by $\mathrm{N}_{2}$ cryogenic absorption.

\begin{tabular}{|c|c|c|c|c|}
\hline Entry & Material & $\begin{array}{c}\text { Specific } \\
\text { surface } \\
\text { area } \\
\left(\mathrm{m}^{2} / \mathrm{g}\right)\end{array}$ & $\begin{array}{c}\text { Specific } \\
\text { pore } \\
\text { volume } \\
\left(\mathrm{cm}^{3} / \mathrm{g}\right)\end{array}$ & $\begin{array}{c}\text { Average } \\
\text { pore } \\
\text { diameter } \\
(\mathrm{nm})\end{array}$ \\
\hline 1 & MCM-41_50\% & 16 & 0.02 & 6.1 \\
\hline 2 & FMCM-41_10\% & 166 & 0.1 & 3.3 \\
\hline 3 & FMCM-41_20\% & 49 & 0.08 & 6 \\
\hline 4 & FMCM-41_30\% & 24 & 0.06 & 8.5 \\
\hline 5 & FMCM-41_40\% & 16 & 0.02 & 5.3 \\
\hline
\end{tabular}
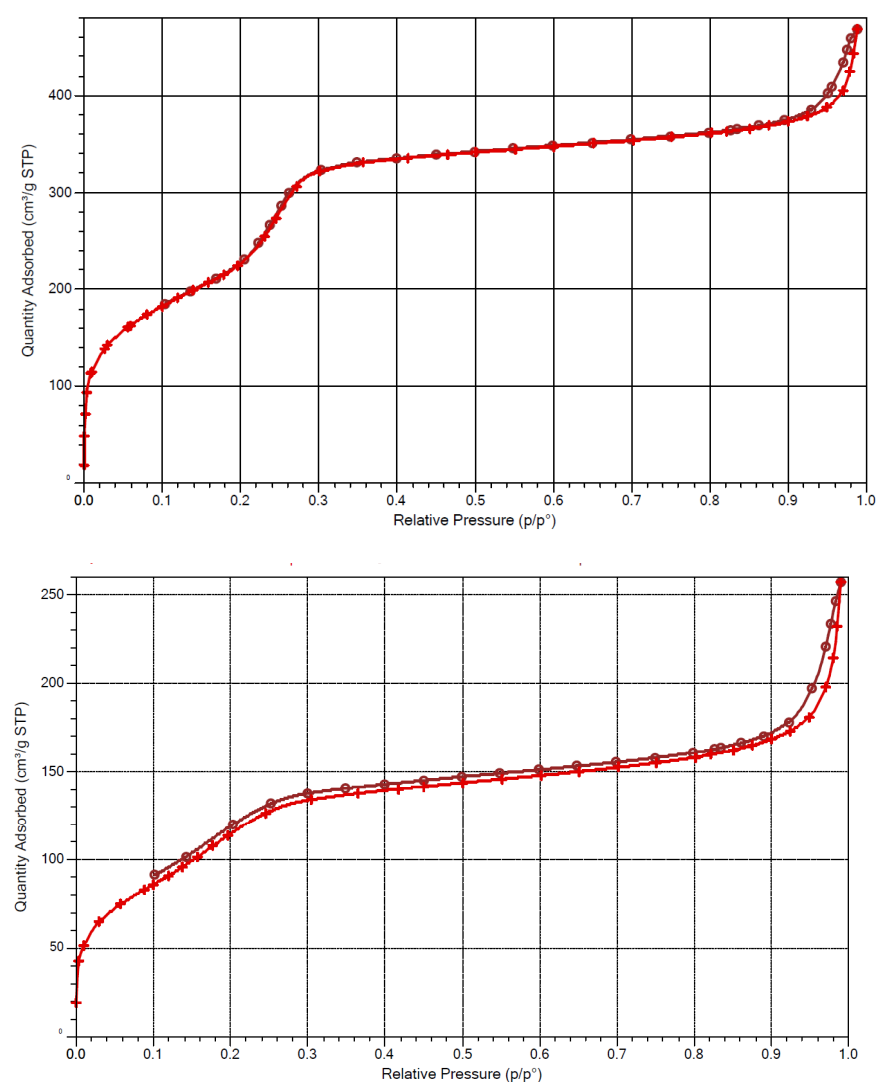

Figure 2. $\mathrm{N}_{2}$ adsorbtion-desorption isotherms of MCM-41 (top), and FMCM-41 (bottom).

The amount of amino-propyl-trimethoxysilane grafted on the MCM-41 silica surface is derived from the thermogravimetric analysis (TGA) of both MCM-41 and FMCM-41 displayed in Figure 3 along with the derivative thermogravimetry (DTG) curve.

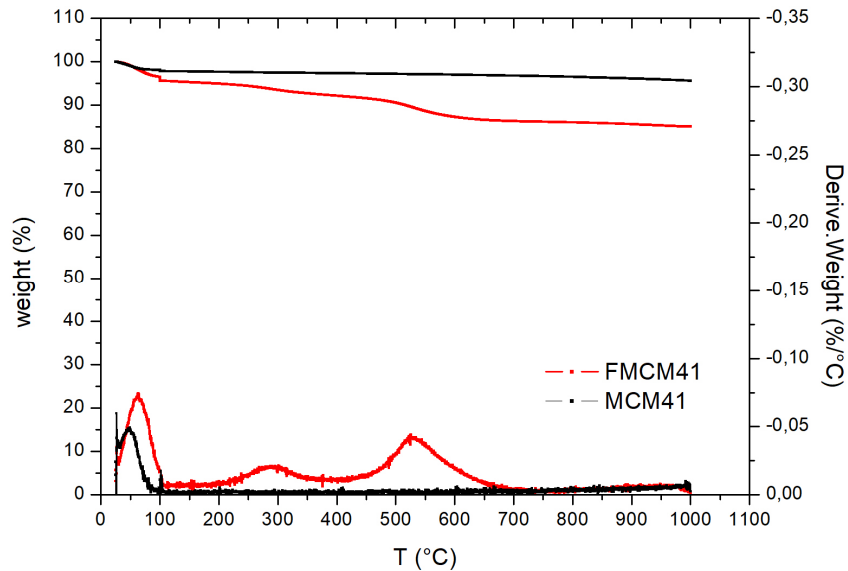

Figure 3. TGA and DTG curves of MCM-41 (black) and FMCM-41 (red).

Three weight losses are observed in the TGA curve of FMCM- 41. The first, close to $100{ }^{\circ} \mathrm{C}(-4.4 \%)$, is due to evaporation of water adsorbed at the surface of hydrophilic silica. The second, at about $300{ }^{\circ} \mathrm{C}(-4.3 \%)$, originates from the desorption of physically adsorbed APTMS [18]. The third, above $430{ }^{\circ} \mathrm{C}(-$ $6.2 \%)$, is due to thermal decomposition of the $-\left(\mathrm{CH}_{2}\right)_{3} \mathrm{NH}_{2}$ groups chemically bound ("grafted") to the silica structure, with the $\mathrm{C}-\mathrm{Si}$ bond starting to break up at $450-510{ }^{\circ} \mathrm{C}$ [18].

Following Wang and co-workers [19], the mole number of APTMS grafted on the silica surface was determined from the weight loss $\Delta \mathrm{W}(\%)$ at $430{ }^{\circ} \mathrm{C}, n_{\mathrm{A}}(\mathrm{mol})$ amount $=\mathrm{m}_{430} / \mathrm{M}_{\mathrm{NH}}$ where $\mathrm{m}_{430}(\mathrm{~g})$ is the weight loss of the sample at $430{ }^{\circ} \mathrm{C}$ $(0.9513 \mathrm{mg})$, and $\mathrm{M}_{\mathrm{NH}}(\mathrm{g} / \mathrm{mol})$ is the molecular weight of $\left(\mathrm{CH}_{2}\right)_{3} \mathrm{NH}_{2}$ group $(58 \mathrm{~g} / \mathrm{mol})$. The APTMS content ( $\left.\mathrm{mmol} / \mathrm{g}_{\text {silica }}\right)$ is given by $n_{\mathrm{A}}$ divided by the silica mass $\left(m_{\mathrm{SiO} 2}\right)$ determined by subtracting the mass brought by grafted APTMS from the residual weight at $300{ }^{\circ} \mathrm{C}\left(m_{300}\right)$. In the present case, the calculated amount of amino-propyl groups of $1.07 \mathrm{mmol} / \mathrm{g}$, namely $76 \%$ of the theoretical value $(1.4 \mathrm{mmol} / \mathrm{g})$, pointing to the fact that MCM-41 functionalization via post-grafting method was successful.

The TGA was used to assess also the thermal stability of the silicas loaded with $50 \mathrm{wt} \%$ and $40 \mathrm{wt} \%$ anchovy fish oil carrying out the TGA measurements one month after storing the materials at room temperature under conventional atmosphere.

The overlapping curves in Figure 4 clearly show that both MCM41 loaded with $50 \mathrm{wt} \%$ oil and its amino-propyl-functionalized counterpart doped with $40 \mathrm{wt} \%$ fish oil show excellent thermal stability over time. 

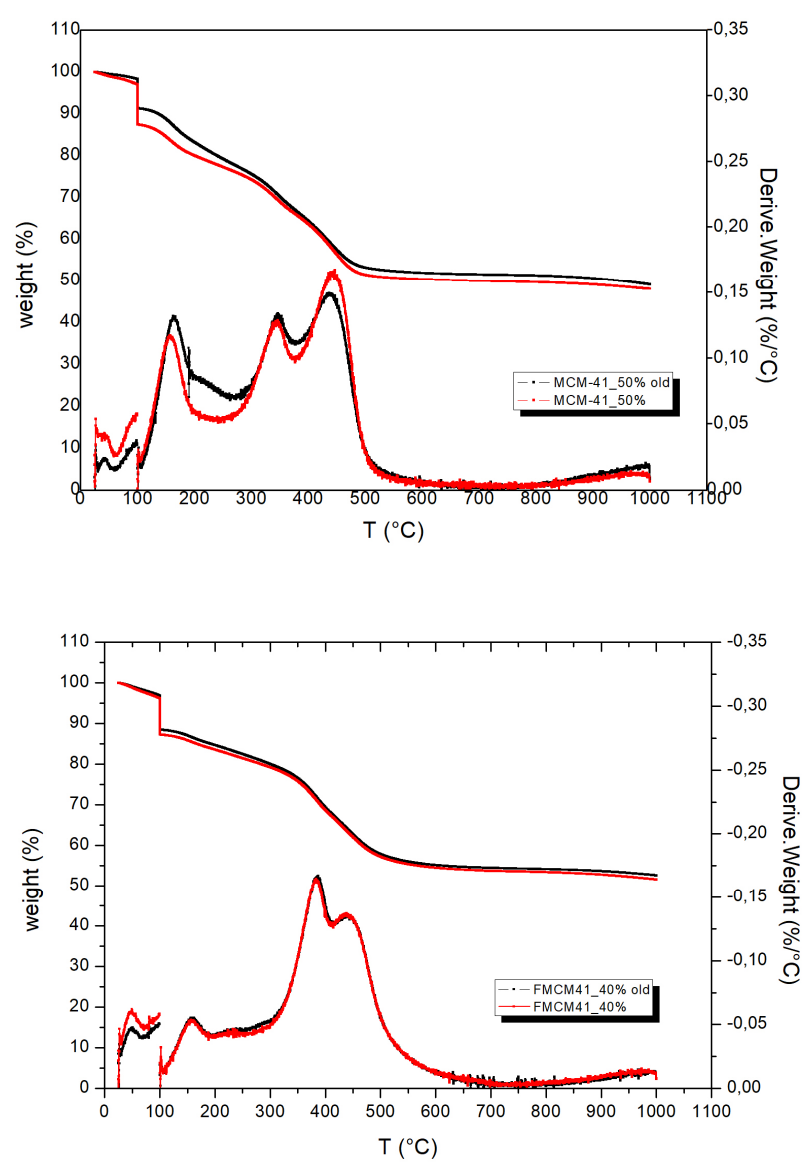

Figure 4. TGA and DTG curves of Omeg@Silicas MCM-41_50\% (top), and FMCM-41_40\% (bottom).

Evidence of successful encapsulation of fish oil was obtained also from comparing the FTIR spectrum of MCM- 41 with that of the same material functionalized with $50 \mathrm{wt} \%$ anchovy fish oil. The black curve in Figure 5 is typical of sol-gel silica with the main infrared bands $\mathrm{WH}$ at $3200-3300 \mathrm{~cm}^{-1}, v_{\text {as }}$ Si-O-Si at 1080 $\mathrm{cm}^{-1}, v \mathrm{Si}-\mathrm{OH}$ at $950 \mathrm{~cm}^{-1}$ and $v_{\mathrm{s}} \mathrm{Si}-\mathrm{O}-\mathrm{Si}$ at $800 \mathrm{~cm}^{-1}$, and $\rho$ Si-OSi at $460 \mathrm{~cm}^{-1}[20]$.

The red curve in Figure 5 displaying the IR spectrum of MCM-41 loaded with $50 \mathrm{wt} \%$ fish oil clearly shows peaks in the fingerprint region (800-1500 $\left.\mathrm{cm}^{-1}\right)$, especially in the $1050-950 \mathrm{~cm}^{-1}$ region, which has been ascribed to $=\mathrm{C}-\mathrm{H}$ out-of-plane bending [21].

Remarkably, the $\mathrm{C}=\mathrm{O}$ carbonyl band at $1720-1746 \mathrm{~cm}^{-1}$ normally significant in omega- 3 lipids is absent, which points to likely coordination of the carbonyl's oxygen with the numerous $\mathrm{Si}-\mathrm{OH}$ groups at the surface of the sol-gel cages.

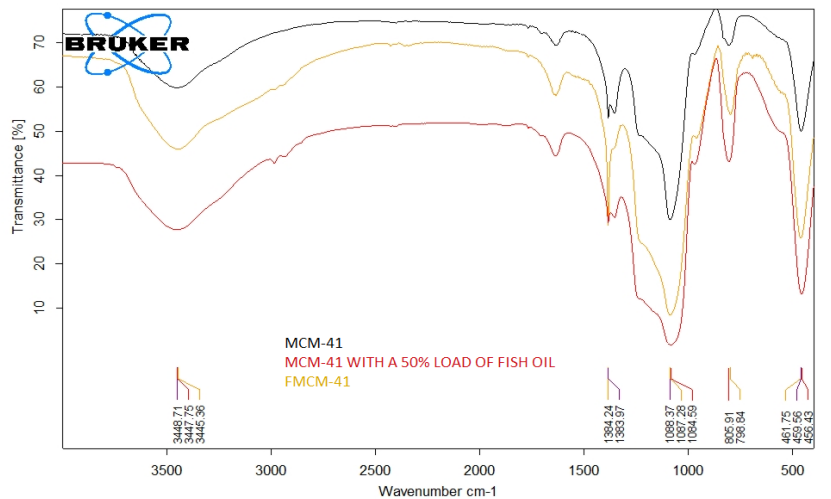

Figure 5. FT-IR spectra of MCM-41, Omeg@Silica MCM-41_50\% and FMCM41.

The SEM microphotographs (Figure 6) show that filling the inner porosity of MCM-41 with 50 wt\% fish oil changes the outer surface morphology of the spherical $\mathrm{SiO}_{2}$ submicroparticles into a smoother, more compact agglomerate of amorphous particles.
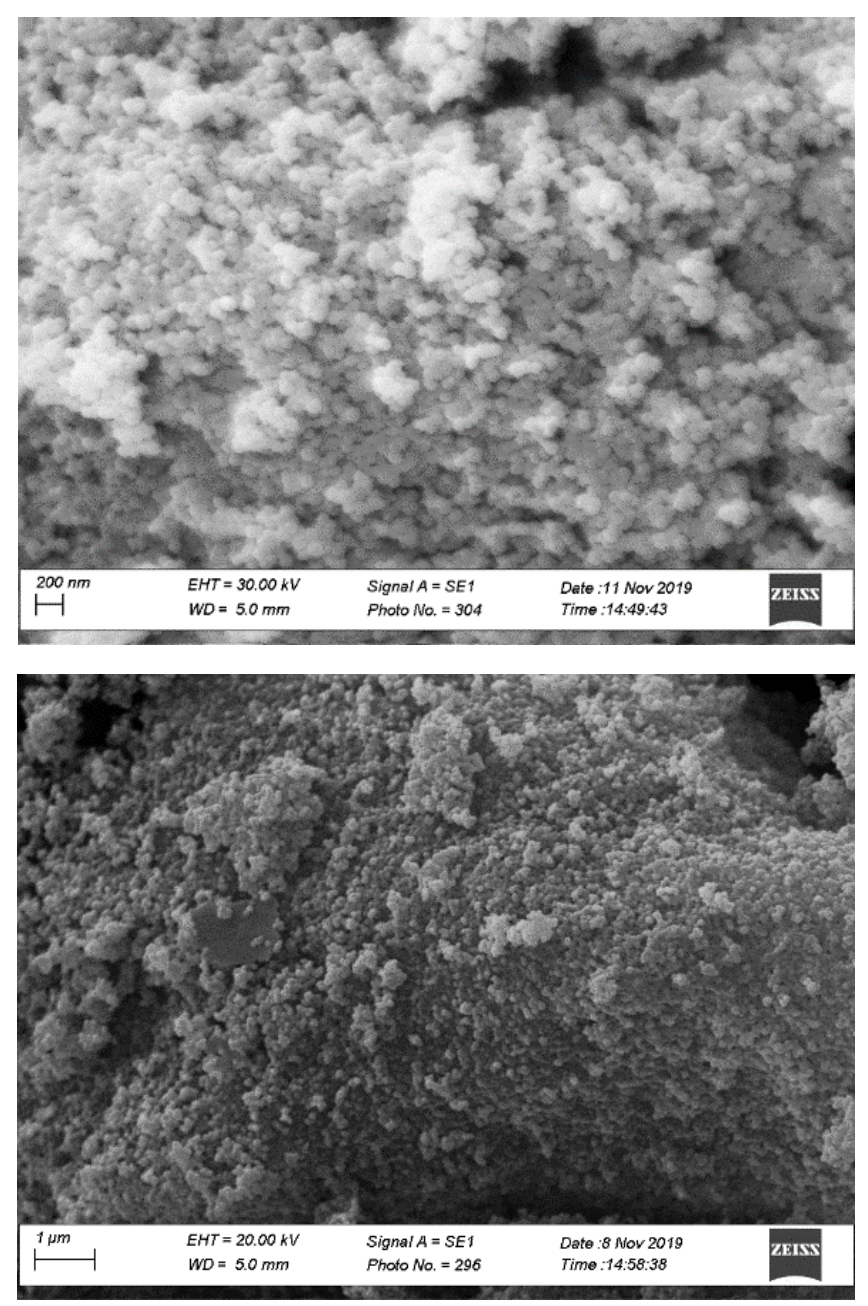

Figure 6. SEM microphotographs of MCM-41 silica (top), and Omeg@Silica MCM-41_50\% (bottom). 
Finally, the zeta potential of MCM-41 and FMCM-41 Omeg@Silicas doped, respectively, with 50 wt\% and with 40 wt $\%$ fish oil indicate (entries 2 and 7 in Table 4) pronounced stability of the aqueous suspensions of the materials.

Table 4. Zeta potential, Z-Ave and PDI of MCM-41 and FMCM-41 and Omeg@Silicas loaded with different amounts of anchovy fish oil

\begin{tabular}{|c|c|c|c|c|}
\hline Entry & $\begin{array}{c}\text { Material } \\
(1 \mathrm{mg} / \mathrm{mL})\end{array}$ & $\begin{array}{c}\text { Zeta potential } \\
(\mathrm{mV})\end{array}$ & $\begin{array}{c}\text { Z-Ave } \\
(\mathrm{nm})\end{array}$ & PDI \\
\hline 1 & MCM-41 & $-33,4$ & 217 & 0.3 \\
\hline 2 & MCM-41_50\% & -37.6 & 269 & 0.3 \\
\hline & $\begin{array}{c}\text { Material } \\
(0.5 \mathrm{mg} / \mathrm{mL})\end{array}$ & & & \\
\hline 3 & FMCM-41 & -14.9 & 297 & 0.4 \\
\hline 4 & FMCM-41_10\% & -8.67 & 1915 & 0.4 \\
\hline 5 & FMCM-41_20\% & -23.7 & 1777 & 0.4 \\
\hline 6 & FMCM-41_30\% & -29.4 & 1100 & 0.5 \\
\hline 7 & FMCM-41_40\% & -40.4 & 522 & 0.5 \\
\hline
\end{tabular}

We briefly remind that the zeta potential -- the electric potential at the shear layer formed in the double layer of the surface of a particle immersed in a liquid -- allows to evaluate the electrostatic stability of particles suspended in water. Particles in suspension having a large positive $(>30 \mathrm{mV})$ or negative $(<-30$ $\mathrm{mV}$ ) value of the zeta potential repel each other: aggregation is prevented and the dispersion remains electrostatically stable.

Showing evidence of the silica nature of the suspended particles [22], all suspensions have negative zeta-potential. The $40.4 \mathrm{mV}$ absolute value of zeta-potential of the amino-propyl-silica doped with $40 \mathrm{wt} \%$ anchovy fish oil points to its pronounced stability. On the other hand, the absolute values for suspensions of the same organically modified silica empty or doped with 10, 20 and $30 \mathrm{wt} \%$ fish oil indicate lack of stability towards aggregation.

In brief, functionalization with fish oil of both pure silica or organically modified silica is beneficial for the electrostatic stability of microparticles suspensions in water provided that high amounts of fish oil are loaded within the silica inner porosity.

The outcomes of DLS measurements indicate (Figure 7) that the population of particles is represented by well dispersed submicroparticles distributed around $269 \mathrm{~nm}$ for the MCM41_50\% Omeg@Silica and around 522 nm for the FMCM41_40\% Omeg@Silica.

The materials respectively have a polydispersity index (PDI) value lower $(0.3)$ or equal to 0.5 , which is an important characteristic in drug ("payload") delivery applications [23]. The Z-average size (measure of the average size of the particle size distribution resulting by DLS) indicates a moderate increase from 217 to $269 \mathrm{~nm}$ for MCM-41 silica going from empty to filled with $50 \mathrm{wt} \%$ fish oil, and almost doubling in size for FMCM-41 aminopropylsilica particles going from empty to doped with the maximum $40 \mathrm{wt} \%$ load (from 297 to $522 \mathrm{~nm}$ ).
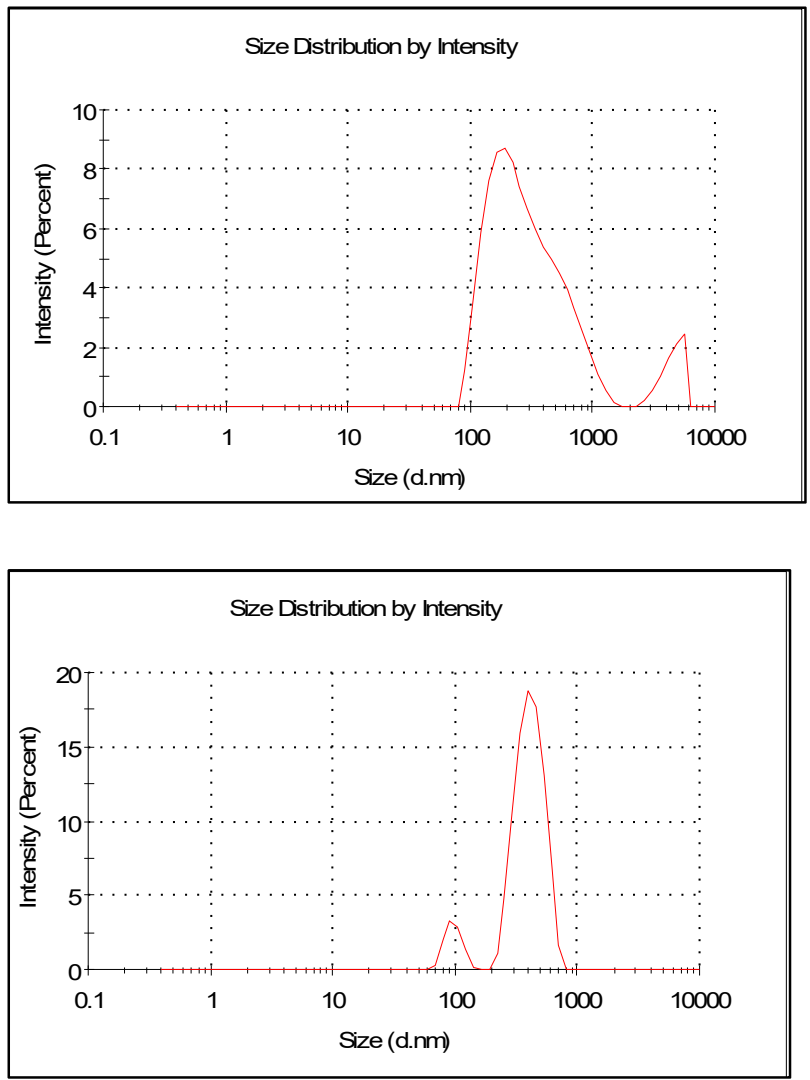

Figure 7. Particle size distribution of Omeg@Silica MCM-41_50\% (top), and Omeg@Silica FMCM-41_40\% (bottom).

\section{Conclusions}

The huge demand of omega-3 lipids, whose main ingredient used by the nutraceutical and dietary supplement industries is fish oil, is accelerating depletion of several marine species [7], including anchovies: one of the most fished species across the world.

Sourcing fish oil from fish processing waste is an urgent and global societal, economic and environmental need [8]. In a series of papers opened by the discovery of the extraction process using biobased limonene [9], we have jointly shown how fish oil sourced from anchovy or shrimp [24] industrial waste has exceptional nutraceutical value [14], and that the method is technically and economically viable [25].

Expanding the uses of valued fish oil via microencapsulation and stabilization is of great practical relevance. In this study, we show how micrencapsulation of sustainably sourced fish oil is readily and easily achieved by adsorption over periodic mesoporous silicas.

Both mesoporous MCM-41 silica and FMCM-41 amino-propylsilica submicroparticles are excellent biocompatible supports for adsorption and delivery of fish oil rich in omega-3, vitamin $D_{3}$ and natural astaxanthin sustainably sourced from anchovy filleting industrial waste [9]. 
The entrapment process is simple and takes place at room temperature and pressure with no need for microencapsulation devices. It is enough to add the newly extracted fish oil the assynthesized materials kept under agitation at room temperature to rapidly obtain silicate powders incorporating a high load of marine oil.

Quick and effective oil entrapment of the oil is due to the huge specific surface area and pore volume of both silicas whose ordered hexagonal pores act as "chemical sponges", adsorbing and concentrating the lipid, vitamin $D_{3}$ and astaxanthin molecules at their inner surface.

The outcome is a white and free flowing powdered material series dubbed herein “Omeg@Silica”.

In general, periodic mesoporous silicas are biocompatible and suitable for the targeted release of bioactive molecules in the gastrointestinal tract [26], even though mesoporous silica comprising the MCM-41 structure is rapidly degraded under in vitro digestion conditions, while organically functionalized silica with 3-amino-propyl groups is generally more stable [27].

Due both to larger interfacial surface area of silica-entrapped fish oil triglyceride molecules and to the interfacial effect of the silica cages guiding access of the external reactants (including enzymes) to the entrapped species [28], once entrapped in mesoporous silicas omega- 3 triglycerides were found to be even more bioaccessible to lipase $(40 \%$ faster lypolisis kinetics ascribed to the lipase molecules adsorbed to the silica surface in their active, open-lid conformation [29]) in comparison to crude fish oil [13].

All this suggests that Omeg@Silica materials of facile preparation and handling are suitable for multiple forthcoming practical applications, ranging from fortified foods to controlled release and delivery of omega-3 lipids protected from oxidation and biological degradation.

\section{Acknowledgements}

We are grateful to Dr Fabio D'Agostino, CNR-IAS, for the SEM measurements. Thanks to Agostino Recca Conserve Alimentari Srl (Sciacca, Italy) for kindly providing leftovers of fresh anchovy fillets.

\section{Author Information}

\section{Corresponding Authors}

*E-mail: rosaria.ciriminna@cnr.it

\section{ORCID}

Rosaria Ciriminna: 0000-0001-6596-1572

Claudia Lino: 0000-0002-8724-7772

Mario Pagliaro: 0000-0002-5096-329X

\section{Notes}

The authors declare no competing financial interest.

\section{References}

[1] J. Dyerberg, H.O. Bang, Hæmostatic Function and Platelet Polyunsaturated Fatty Acids in Eskimos, Lancet 1979, 314, 433-435.

[2] W. E. M. Lands, Fish, Omega-3 and Human Health, AOCS Publishing, Urbana (IL): 2005.

[3] M. Bäck, G. K. Hansson, Omega-3 fatty acids, cardiovascular risk, and the resolution of inflammation, FASEB J. 2019, 33, 1536-1539.

[4] S. Salioni Camargo Novaes, F. Balardin Hellmeister Dantas, I. Dutra Alvim, A. M. Rauen de Oliveira Miguel, S. Tondella Dantas, R. M. Vercelino Alves, Stability of omega-3 enriched milk powder in different commercial packages stored under accelerated conditions of temperature and relative humidity, Int. Dairy J. 2019, 88, 19

[5] I. Fraeye, C. Bruneel, C. Lemahieu, J. Buyse, K. Muylaert, I. Foubert, Dietary enrichment of eggs with omega-3 fatty acids: A review, Food Res. Int. 2012, 48, 961-969.

[6] W. S. Harris, The Omega-6:Omega-3 ratio: A critical appraisal and possible successor, Prostag. Leukotr. Ess. 2018, 132, 34-40.

[7] P. Greenberg, The Omega Principle, Penguin, New York: 2018.

[8] R. Ciriminna, F. Meneguzzo, R. Delisi, M. Pagliaro, Enhancing and improving the extraction of omega-3 from fish oil, Sustainable Chem. Pharm. 2017, 5, 54-59.

[9] R. Ciriminna, A. Scurria, G. Avellone, M. Pagliaro, A Circular Economy Approach to Fish Oil Extraction, ChemistrySelect 2019, 4, 5106-5109.

[10] R. Ciriminna, M. Lomelli, P. Demma Carà, J. LopezSanchez, M. Pagliaro, Limonene: A Versatile Chemical of the Bioeconomy, Chem. Commun. 2014, 50, 15288-15296.

[11] E. Arab-Tehrany, M. Jacquot, C. Gaiani, M. Imran, S. Desobry, M. Linder, Beneficial effects and oxidative stability of omega-3 long-chain polyunsaturated fatty acids, Trends Food Sci. Technol. 2012, 25, 24-33.

[12] S. Chatterjee, Z. M. A. Judeh, Microencapsulation of fish oil, Lipid Technol. 2016, 28, 13-15.

[13] P. Joyce, H. Gustafsson, C. A. Prestidge, Enhancing the lipase-mediated bioaccessibility of omega- 3 fatty acids by microencapsulation of fish oil droplets within porous silica particles, J. Funct. Foods 2018, 47, 491-502.

[14] A. Scurria, C. Lino, R. Pitonzo, M. Pagliaro, G. Avellone, R. Ciriminna, Vitamin $D_{3}$ in Fish Oil Extracted with Limonene from Anchovy Leftovers, Chem. Data Collect. 2020, 25, 100311.

[15] S. A. Jadhav, I. Miletto, V. Brunella, D. Scalarone, G. Berlier, Porous Silica Particles: Synthesis, Physicochemical Characterization and Evaluation of Suspension Stability, Phys. Chem. Ind. J. 2017, 12, 102.

[16] H. I. Meléndez-Ortizn, Y. Perera-Mercado, J. A. MercadoSilva, Y. Olivares-Maldonado, G. Castruita, L. A. GarcíaCerda, Functionalization with amine-containing organosilane of mesoporous silica MCM- 41 and MCM-48 obtained at room temperature, Ceram. Int. 2014, 40, 97019707.

[17] K. S. W. Sing, D. H. Everett, R. A. W. Haul, L. Moscou, R. A. Pierotti, J. Rouquérol, T. Siemieniewska, Reporting physisorption data for gas/solid systems with special reference to the determination of surface area and porosity, Pure Appl. Chem. 1985, 57, 603-619.

[18] V. Dugas, Y. Chevalier, Chemical reactions in dense monolayers: in situ thermal cleavage of grafted esters for 
preparation of solid surfaces functionalized with carboxylic acids, Langmuir 2011, 27, 14188-14200.

[19] B. Qiao, T. Wang, H. Gao, Y. Jin, High density silanization of nano-silica particles using-aminopropyltriethoxysilane (APTES), Appl. Surf. Sci. 2015, 351, 646-654.

[20] A. Fidalgo, T. G. Nunes, L. M. Ilharco, The Structure of Hybrid Gels by Drift and NMR Spectroscopies, J. Sol-Gel Sci. Technol. 2000, 19, 403-407.

[21] M. Plans, M. J. Wenstrup, L. E. Rodriguez-Saona, Application of Infrared Spectroscopy for Characterization of Dietary Omega-3 Oil Supplements, J. Am. Oil Chem. Soc. 2015, 92, 957-966.

[22] N. I. Vazquez, Z. Gonzalez, B. Ferrari, Y. Castro, Synthesis of mesoporous silica nanoparticles by sol-gel as nanocontainer for future drug delivery applications, Bol. Soc. Esp. Ceram. 2017, 56, 139-145.

[23] M. Danaei, M. Dehghankhold, S. Ataei, F. Hasanzadeh Davarani, R. Javanmard, A. Dokhani, S. Khorasani, M. R. Mozafari, Impact of Particle Size and Polydispersity Index on the Clinical Applications of Lipidic Nanocarrier Systems, Pharmaceutics 2018, 10, 57.

[24] A. Scurria, A.-S. Fabiano Tixier, C. Lino, M. Pagliaro, G. Avellone, F. D'Agostino, F. Chemat, R. Ciriminna, High Yields of Shrimp Oil Rich in Omega-3 and Natural Astaxanthin from Shrimp Waste, ACS Omega 2020, 5, 17500-17505.

[25] R. Ciriminna, A. Scurria, A. S. Fabiano-Tixier, C. Lino, G. Avellone, F. Chemat, M. Pagliaro, Omega-3 Extraction from Anchovy Fillet Leftovers with Limonene: Chemical, Economic and Technical Aspects, ACS Omega 2019, 4, 15359-15363.

[26] É. Pérez-Esteve, M. Ruiz-Rico, R. Martìnez-Mànez, J. M. Barat, Mesoporous silica-based supports for the controlled and targeted release of bioactive molecules in the gastrointestinal tract, J. Food Sci. 2015, 80, E2504-E2516

[27] É. Pérez-Esteve, M. Ruiz-Rico, C. de la Torre, E. Llorca, F. Sancenòn, M. D. Marcos, P. Amoròs, C. Guillem, R. Martìnez-Mànez, J. Barat, Stability of different mesoporous silica particles during an in vitro digestion Micropor. Mesopor. Mater. 2016, 230, 196-207.

[28] M. Pagliaro, R. Ciriminna, G. Palmisano, The chemical effects of molecular sol-gel entrapment, Chem. Soc. Rev. 2007, 36, 932-940.

[29] P. Joyce, I. Kempson, C.A. Prestidge, Orientating lipase molecules through surface chemical control for enhanced activity: A QCM-D and ToF-SIMS investigation, Colloids Surf. B 2016, 142, 173-181. 
Valued fish oil? Encapsulate it in silica! Fish oil rich in DHA and EPA polyunsaturated fatty acids, vitamin $\mathrm{D}_{3}$ and natural astaxanthin sustainably extracted from anchovy fillet leftovers using biobased limonene only, is conveniently stabilized by adsorption on periodic

mesoporous silicas. The simplicity of the process, the high load of fish oil encapsulated in biocompatible silicas support numerous applications of this new class of "Omeg@Silica" materials.

\section{Omeg@Silica: In-Silica Stabilization of Sustainable Fish} Oil

C. Lino, M. Pagliaro, R. Ciriminna

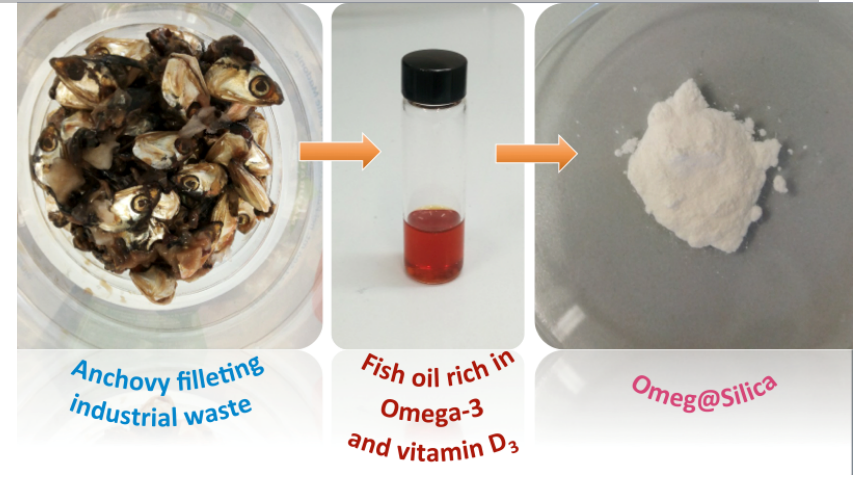

